\title{
A New Sixth-Order Steffensen-Type Iterative Method for Solving Nonlinear Equations
}

\author{
Tahereh Eftekhari \\ Faculty of Mathematics, University of Sistan and Baluchestan, Zahedan 987-98155, Iran \\ Correspondence should be addressed to Tahereh Eftekhari; t.eftekhari2009@gmail.com
}

Received 11 November 2013; Revised 6 January 2014; Accepted 9 January 2014; Published 12 February 2014

Academic Editor: Ahmed Zayed

Copyright (c) 2014 Tahereh Eftekhari. This is an open access article distributed under the Creative Commons Attribution License, which permits unrestricted use, distribution, and reproduction in any medium, provided the original work is properly cited.

Based on iterative method proposed by Basto et al. (2006), we present a new derivative-free iterative method for solving nonlinear equations. The aim of this paper is to develop a new method to find the approximation of the root $\alpha$ of the nonlinear equation $f(x)=0$. This method has the efficiency index which equals $6^{1 / 4}=1.5651$. The benefit of this method is that this method does not need to calculate any derivative. Several examples illustrate that the efficiency of the new method is better than that of previous methods.

\section{Introduction}

Solving nonlinear equations is one of the most important and challenging problems in scientific and engineering applications. In this paper, we consider an iterative method to find the root of a nonlinear equation $f(x)=0$.

Newton's method is the best known iterative method for solving nonlinear equations [1], given by

$$
x_{n+1}=x_{n}-\frac{f\left(x_{n}\right)}{f^{\prime}\left(x_{n}\right)}, \quad n=0,1,2, \ldots
$$

which converges quadratically. But it has a major weakness, one has to calculate the derivative of $f(x)$ at each approximation. Frequently, $f^{\prime}\left(x_{n}\right)$ is far more difficult to evaluate and needs more arithmetic operations to calculate than $f(x)$.

It is well known that the forward-difference approximation for $f^{\prime}\left(x_{n}\right)$ at $x$ is

$$
f^{\prime}(x) \approx \frac{f(x+h)-f(x)}{h} .
$$

If the derivative $f^{\prime}\left(x_{n}\right)$ is replaced by the forward-difference approximation with $h=f\left(x_{n}\right)$ that is

$$
f^{\prime}\left(x_{n}\right) \approx \frac{f\left(x_{n}+f\left(x_{n}\right)\right)-f\left(x_{n}\right)}{f\left(x_{n}\right)},
$$

the Newton's method becomes

$$
x_{n+1}=x_{n}-\frac{f\left(x_{n}\right)^{2}}{f\left(x_{n}+f\left(x_{n}\right)\right)-f\left(x_{n}\right)}, \quad n=0,1,2, \ldots
$$

which is the famous Steffensen's method [2]. The Steffensen's method is based on forward-difference approximation to derivative. This method is a tough competitor of Newton's method. Both methods are of quadratic convergence, and both require two functions evaluation per iteration, but in contrast to Newton's method, Steffensen's method is derivative-free. Based on this method, many derivative-free iterative methods have been proposed.

In [3], a sixth-order derivative-free iterative method has been proposed by Cordero et al. as follows:

$$
\begin{gathered}
y_{n}=x_{n}-\frac{2 f\left(x_{n}\right)^{2}}{f\left(x_{n}+f\left(x_{n}\right)\right)-f\left(x_{n}-f\left(x_{n}\right)\right)}, \\
z_{n}=y_{n}-\frac{y_{n}-x_{n}}{2 f\left(y_{n}\right)-f\left(x_{n}\right)} f\left(y_{n}\right), \\
x_{n+1}=z_{n}-\frac{y_{n}-x_{n}}{2 f\left(y_{n}\right)-f\left(x_{n}\right)} f\left(z_{n}\right),
\end{gathered}
$$

which has efficiency index 1.430 . 
Soleymani and Hosseinabadi [4] suggested another sixthorder derivative-free scheme in the form below:

$$
\begin{gathered}
y_{n}=x_{n}-\frac{f\left(x_{n}\right)}{f\left[x_{n}, w_{n}\right]}, \\
z_{n}=x_{n}-\frac{f\left(x_{n}\right)}{f\left[x_{n}, w_{n}\right]}\left(1+\frac{f\left(y_{n}\right)}{f\left(x_{n}\right)}\left(1+2 \frac{f\left(y_{n}\right)}{f\left(x_{n}\right)}\right)\right), \\
x_{n+1}=z_{n}-\frac{f\left(z_{n}\right)}{f\left[y_{n}, z_{n}\right]}\left(1-\frac{1+f\left[x_{n}, w_{n}\right]}{f\left[x_{n}, w_{n}\right]} \frac{f\left(z_{n}\right)}{f\left(w_{n}\right)}\right),
\end{gathered}
$$

wherein the efficiency index is 1.5651 .

In [5], a sixth-order derivative-free algorithm has been derived by Yasmin and Iftikhar, which is written as

$$
\begin{gathered}
y_{n}=x_{n}-\frac{f\left(x_{n}\right)}{f\left[x_{n}, w_{n}\right]}, \\
z_{n}=y_{n}-f\left(y_{n}\right) \\
\times\left(\frac{1}{f\left[x_{n}, w_{n}\right]}\right. \\
\left.\quad-\frac{4\left(f\left(x_{n}\right)+f\left(y_{n}\right)\right)}{f\left[x_{n}, w_{n}\right]+f\left[x_{n}, w_{n}\right]\left(f\left(x_{n}\right)-f\left(y_{n}\right)\right)}\right), \\
x_{n+1}=z_{n}-\frac{f\left(z_{n}\right)}{f\left[y_{n}, z_{n}\right]-f\left[x_{n}, y_{n}\right]+f\left[x_{n}, z_{n}\right]},
\end{gathered}
$$

which has efficiency index 1.5651.

The processes of removing the derivatives usually increase the number of function evaluations per iteration. In our method, we used the technique of composition of Newton's method with the known methods, which not only increase the order of the method as high as possible but also reduce the number of function evaluations and improve the efficiency index of the composed method. In view of this fact, the new steffensen-like methods are significantly better when compared with the established methods described above.

This paper is organized as follows: some basic definitions relevant to the present work are presented in Section 2. In Section 3, we present a new three-step sixth-order iterative method for solving nonlinear equations. The new method is free from derivative. We prove that the order of convergence of the new method is six. Numerical examples show better performance of our method in Section 4. Section 5 is a short conclusion.

\section{Basic Definitions}

Definition 1. Let $f(x)$ be a real function with a simple root $\alpha$ and let $\left\{x_{n}\right\}_{n \in \mathbb{N}}$ be a sequence of real numbers that converges towards $\alpha$. Then, we say that the order of convergence of the sequence is $p$, if there exists a number $p \in \mathbb{R}^{+}$such that

$$
\lim _{n \rightarrow \infty} \frac{x_{n+1}-\alpha}{\left(x_{n}-\alpha\right)^{p}}=C,
$$

where for some $C \neq 0, C$ is known as the asymptotic error constant.

If $p=1,2$, or 3 , the sequence is said to have linear convergence, quadratic convergence, or cubic convergence, respectively.

Definition 2. Let $e_{n}=x_{n}-\alpha$ be the error in the $n$th iteration; One calls the relation

$$
e_{n+1}=C e_{n}^{p}+O\left(e_{n}^{p+1}\right)
$$

the error equation.

Definition 3. Let $q$ be the number of function evaluations of the new method. The efficiency of the new method is measured by the concept of efficiency index [6] and defined as

$$
E=p^{1 / q},
$$

where $p$ is the order of the method.

Definition 4. Suppose that $x_{n+1}, x_{n}$, and $x_{n-1}$ are three successive iterations closer to the root $\alpha$. Then, the computational order of convergence [7] is approximated by using (9) as follows:

$$
\rho \approx \frac{\operatorname{Ln}\left|\left(x_{n+1}-\alpha\right)\left(x_{n}-\alpha\right)^{-1}\right|}{\operatorname{Ln}\left|\left(x_{n}-\alpha\right)\left(x_{n-1}-\alpha\right)^{-1}\right|}
$$

where $n \in \mathbb{N}$.

\section{Iterative Method and Convergence Analyses}

Consider the following iterative method proposed by Basto et al. [8] to construct a new sixth-order method:

$$
x_{n+1}=x_{n}-\frac{f\left(x_{n}\right)}{f^{\prime}\left(x_{n}\right)}-\frac{\left[f\left(x_{n}\right)\right]^{2} f^{\prime \prime}\left(x_{n}\right)}{2\left[f^{\prime}\left(x_{n}\right)\right]^{3}-2 f\left(x_{n}\right) f^{\prime}\left(x_{n}\right) f^{\prime \prime}\left(x_{n}\right)} .
$$

This method is third-order and the efficiency index is $3^{1 / 3}=1.4422$.

First, we replace $f^{\prime \prime}\left(x_{n}\right)$ from (12) with a finite difference between the first derivatives [9]; that is,

$$
f^{\prime \prime}\left(x_{n}\right)=\frac{f^{\prime}\left(y_{n}\right)-f^{\prime}\left(x_{n}\right)}{y_{n}-x_{n}}
$$

where

$$
y_{n}=x_{n}-\frac{f\left(x_{n}\right)}{f^{\prime}\left(x_{n}\right)},
$$

using (13) and (14) in (12), we obtained an equivalent form:

$$
\begin{gathered}
y_{n}=x_{n}-\frac{f\left(x_{n}\right)}{f^{\prime}\left(x_{n}\right)}, \\
x_{n+1}=y_{n}+\frac{f\left(x_{n}\right)\left(f^{\prime}\left(y_{n}\right)-f^{\prime}\left(x_{n}\right)\right)}{2 f^{\prime}\left(x_{n}\right) f^{\prime}\left(y_{n}\right)} .
\end{gathered}
$$


By combining the method (15) with Newton's method, we obtain a new three-step iterative algorithm without memory as follows:

$$
\begin{gathered}
y_{n}=x_{n}-\frac{f\left(x_{n}\right)}{f^{\prime}\left(x_{n}\right)}, \\
z_{n}=y_{n}+\frac{f\left(x_{n}\right)\left(f^{\prime}\left(y_{n}\right)-f^{\prime}\left(x_{n}\right)\right)}{2 f^{\prime}\left(x_{n}\right) f^{\prime}\left(y_{n}\right)}, \\
x_{n+1}=z_{n}-\frac{f\left(z_{n}\right)}{f^{\prime}\left(z_{n}\right)},
\end{gathered}
$$

which is required of three evaluations of the first derivative of the function. To remedy these derivatives, firstly, we approximate $f^{\prime}\left(x_{n}\right)$ by the divided difference of order one:

$$
f^{\prime}\left(x_{n}\right) \approx f\left[w_{n}, x_{n}\right]=\frac{f\left(w_{n}\right)-f\left(x_{n}\right)}{w_{n}-x_{n}},
$$

where $w_{n}=x_{n}+f\left(x_{n}\right)$.

Secondly, approximate $f^{\prime}\left(z_{n}\right)$ by the linear combination of divided differences:

$$
f^{\prime}\left(z_{n}\right) \approx f\left[y_{n}, z_{n}\right]-f\left[x_{n}, y_{n}\right]+f\left[x_{n}, z_{n}\right],
$$

and for $f^{\prime}\left(y_{n}\right)$ we use the following approximation [10]:

$$
f^{\prime}\left(y_{n}\right) \approx \frac{f^{\prime}\left(x_{n}\right)\left(f\left(x_{n}\right)-f\left(y_{n}\right)\right)}{f\left(x_{n}\right)+f\left(y_{n}\right)} .
$$

Thus, our new three-step derivative-free iterative algorithm without memory is given as

$$
\begin{gathered}
y_{n}=x_{n}-\frac{f\left(x_{n}\right)}{f\left[x_{n}, w_{n}\right]}, \\
z_{n}=y_{n}-\frac{f\left(x_{n}\right) f\left(y_{n}\right)}{f\left[x_{n}, w_{n}\right]\left(f\left(x_{n}\right)-f\left(y_{n}\right)\right)}, \\
x_{n+1}=z_{n}-\frac{f\left(z_{n}\right)}{f\left[y_{n}, z_{n}\right]-f\left[x_{n}, y_{n}\right]+f\left[x_{n}, z_{n}\right]},
\end{gathered}
$$

where $w_{n}=x_{n}+f\left(x_{n}\right)$.

Theorem 5 demonstrates its convergence analysis.

Theorem 5. Let $\alpha \in I$ be a simple root of a sufficiently differentiable function $f: I \subseteq \mathbb{R} \rightarrow \mathbb{R}$ in an open interval $I$. If the initial approximation $x_{0}$ is sufficiently close to $\alpha$, then the derivative-free method defined by (20) has order of convergence six.

Proof. Let $\alpha$ be the simple root of $f(x)$; that is, $f(\alpha)=0$, $f^{\prime}(\alpha) \neq 0$, and the error equation is $e_{n}=x_{n}-\alpha$.

By Taylor's expansion of $f\left(x_{n}\right)$ about $x=\alpha$ and putting $f(\alpha)=0$, we have

$$
f\left(x_{n}\right)=c_{1} e_{n}+c_{2} e_{n}^{2}+c_{3} e_{n}^{3}+c_{4} e_{n}^{4}+c_{5} e_{n}^{5}+c_{6} e_{n}^{6}+O\left(e_{n}^{7}\right),
$$

TABLE 1: The examples considered in this study.

\begin{tabular}{lc}
\hline Test functions & Zeros \\
\hline$f_{1}(x)=x^{2}-e^{x}-3 x+2$ & $\alpha \approx 0.25753028543986079$ \\
$f_{2}(x)=x e^{x^{2}}-\sin ^{2}(x)+3 \cos (x)+5$ & $\alpha \approx-1.207647827130919$ \\
$f_{3}(x)=\sin (x) e^{x}+\operatorname{Ln}\left(x^{2}+1\right)$ & $\alpha \approx 0$ \\
$f_{4}(x)=10 x e^{-x^{2}}-1$ & $\alpha \approx 1.6796306104284499$ \\
$f_{5}(x)=\cos (x)-x$ & $\alpha \approx 0.73908513321516064$ \\
$f_{6}(x)=e^{-x^{2}+x+2}-1$ & $\alpha \approx-1.000000000000000$ \\
$f_{7}(x)=\operatorname{Ln}\left(x^{2}+x+2\right)-x+1$ & $\alpha \approx 4.1525907367571583$ \\
\hline
\end{tabular}

where

$$
c_{k}=\frac{f^{k}(\alpha)}{k !}, \quad k=1,2,3, \ldots
$$

Expanding the Taylor series of $f\left(w_{n}\right)$ about the solution $\alpha$, we have

$$
f\left(w_{n}\right)=\sum_{i=1}^{\infty} c_{i}\left(e_{n}+f\left(x_{n}\right)\right)^{i}
$$

substituting $f\left(x_{n}\right)$ given by (21) gives us

$$
\begin{aligned}
f\left(w_{n}\right)= & c_{1}\left(1+c_{1}\right) e_{n}+\left(1+c_{1}\left(3+c_{1}\right)\right) c_{2} e_{n}^{2} \\
& +\left(2\left(1+c_{1}\right) c_{2}^{2}+c_{1} c_{3}+\left(1+c_{1}\right)^{3} c_{3}\right) e_{n}^{3} \\
& +\cdots+O\left(e_{n}^{7}\right) .
\end{aligned}
$$

Note that to save the space, we only write some of the obtained terms for the error equations and show the others by ....

Substituting (21) and (24) in the first step of (20) gives us

$$
\begin{aligned}
y_{n}-\alpha= & x_{n}-\alpha-\frac{f\left(x_{n}\right)}{f\left[w_{n}, x_{n}\right]}=\left(1+\frac{1}{c_{1}}\right) c_{2} e_{n}^{2} \\
& +\frac{-\left(2+c_{1}\left(2+c_{1}\right)\right) c_{2}^{2}+c_{1}\left(1+c_{1}\right)\left(2+c_{1}\right) c_{3}}{c_{1}^{2}} e_{n}^{3} \\
& +\cdots+O\left(e_{n}^{7}\right)
\end{aligned}
$$

Using the Taylor expansion of $f\left(y_{n}\right)$ about the solution $\alpha$, we have

$$
f\left(y_{n}\right)=\sum_{i=1}^{\infty} c_{i}\left(y_{n}-\alpha\right)^{i}
$$

substituting (25) into the preceding equation, we have

$$
\begin{aligned}
f\left(y_{n}\right)= & \left(1+c_{1}\right) c_{2} e_{n}^{2} \\
& +\left(\left(-2-\frac{2}{c_{1}}-c_{1}\right) c_{2}^{2}+\left(1+c_{1}\right)\left(2+c_{1}\right) c_{3}\right) e_{n}^{3} \\
& +\cdots+O\left(e_{n}^{7}\right) .
\end{aligned}
$$


TABLE 2: Comparison of various iterative methods.

\begin{tabular}{|c|c|c|c|c|c|}
\hline & New method & $(\mathrm{CM})$ & $(\mathrm{SHM})$ & (YIM) & $(\mathrm{SM})$ \\
\hline \multicolumn{6}{|l|}{$f_{1}, x_{0}=0$} \\
\hline$\left|x_{n}-\alpha\right|$ & $0.23 e-291$ & $0.46 e-165$ & $0.36 e-267$ & $0.45 e-155$ & $0.55 e-80$ \\
\hline$\left|f\left(x_{n}\right)\right|$ & $0.88 e-291$ & $0.18 e-164$ & $0.14 e-266$ & $0.17 e-154$ & $0.21 e-79$ \\
\hline $\mathrm{COC}$ & 6.000000 & 6.000006 & 6.000000 & 5.999992 & 2.000000 \\
\hline TNFE & 12 & 15 & 12 & 12 & 12 \\
\hline \multicolumn{6}{|c|}{$f_{2}, x_{0}=-1.2$} \\
\hline$\left|x_{n}-\alpha\right|$ & $0.36 e-345$ & $0.34 e-180$ & $0.12 e-157$ & $0.67 e-190$ & $0.32 e-40$ \\
\hline$\left|f\left(x_{n}\right)\right|$ & $0.73 e-344$ & $0.69 e-179$ & $0.24 e-156$ & $0.14 e-188$ & $0.65 e-39$ \\
\hline $\mathrm{COC}$ & 6.000000 & 5.999994 & 6.000004 & 6.000000 & 2.000000 \\
\hline TNFE & 12 & 15 & 12 & 12 & 12 \\
\hline \multicolumn{6}{|l|}{$f_{3}, x_{0}=0.1$} \\
\hline$\left|x_{n}-\alpha\right|$ & $0.43 e-145$ & $0.41 e-158$ & $0.52 e-121$ & $0.13 e-88$ & $0.71 e-32$ \\
\hline$\left|f\left(x_{n}\right)\right|$ & $0.43 e-145$ & $0.41 e-158$ & $0.52 e-121$ & $0.13 e-88$ & $0.71 e-32$ \\
\hline $\mathrm{COC}$ & 5.999990 & 5.999996 & 5.999862 & 5.999567 & 2.000000 \\
\hline TNFE & 12 & 15 & 12 & 12 & 12 \\
\hline \multicolumn{6}{|l|}{$f_{4}, x_{0}=1.8$} \\
\hline$\left|x_{n}-\alpha\right|$ & $0.13 e-188$ & $0.12 e-280$ & $0.99 e-171$ & $0.43 e-93$ & $0.38 e-48$ \\
\hline$\left|f\left(x_{n}\right)\right|$ & $0.35 e-188$ & $0.35 e-280$ & $0.27 e-170$ & $0.12 e-92$ & $0.11 e-47$ \\
\hline $\mathrm{COC}$ & 6.000000 & 6.000000 & 5.999998 & 5.999951 & 2.000000 \\
\hline TNFE & 12 & 15 & 12 & 12 & 12 \\
\hline \multicolumn{6}{|l|}{$f_{5}, x_{0}=1$} \\
\hline$\left|x_{n}-\alpha\right|$ & $0.21 e-265$ & $0.14 e-204$ & $0.31 e-257$ & $0.14 e-133$ & $0.54 e-88$ \\
\hline$\left|f\left(x_{n}\right)\right|$ & $0.36 e-265$ & $0.24 e-204$ & $0.515 e-257$ & $0.23 e-133$ & $0.91 e-88$ \\
\hline $\mathrm{COC}$ & 6.000000 & 6.000000 & 6.000000 & 6.000024 & 2.000000 \\
\hline TNFE & 12 & 15 & 12 & 12 & 12 \\
\hline \multicolumn{6}{|c|}{$f_{6}, x_{0}=-0.75$} \\
\hline$\left|x_{n}-\alpha\right|$ & $0.48 e-109$ & $0.11 e-104$ & $0.87 e-74$ & $0.18 e-22$ & $0.11 e-12$ \\
\hline$\left|f\left(x_{n}\right)\right|$ & $0.15 e-108$ & $0.34 e-104$ & $0.26 e-73$ & $0.54 e-22$ & $0.34 e-12$ \\
\hline $\mathrm{COC}$ & 5.999904 & 5.999991 & 5.996977 & 5.920939 & 1.999927 \\
\hline TNFE & 12 & 15 & 12 & 12 & 12 \\
\hline \multicolumn{6}{|l|}{$f_{7}, x_{0}=3.2$} \\
\hline$\left|x_{n}-\alpha\right|$ & $0.14 e-265$ & $0.41 e-199$ & $0.61 e-316$ & $0.12 e-168$ & $0.21 e-98$ \\
\hline$\left|f\left(x_{n}\right)\right|$ & $0.84 e-266$ & $0.24 e-199$ & $0.37 e-316$ & $0.72 e-169$ & $0.13 e-98$ \\
\hline $\mathrm{COC}$ & 6.000000 & 6.000000 & 6.000000 & 6.000001 & 2.000000 \\
\hline TNFE & 12 & 15 & 12 & 12 & 12 \\
\hline
\end{tabular}

Using (21), (24), (25), and (27) in the second step of (20) gives us

$$
\begin{aligned}
z_{n}-\alpha= & \frac{\left(1+c_{1}\right) c_{2}^{2}}{c_{1}^{2}} e_{n}^{3} \\
& +\frac{-\left(3+c_{1}\left(3+c_{1}\right)\right) c_{2}^{3}+c_{1}\left(1+c_{1}\right)\left(3+c_{1}\right) c_{2} c_{3}}{c_{1}^{3}} e_{n}^{4} \\
& +\cdots+O\left(e_{n}^{7}\right) .
\end{aligned}
$$

This shows that at the end of the second step the method is of third order convergence. Therefore, the third step is introduced to achieve the higher order. The Taylor expansion about the simple root for $f\left(z_{n}\right)$ is given as follows:

$$
\begin{aligned}
f\left(z_{n}\right)= & \frac{\left(1+c_{1}\right) c_{2}^{2}}{c_{1}} e_{n}^{3} \\
& +\frac{-\left(3+c_{1}\left(3+c_{1}\right)\right) c_{2}^{3}+c_{1}\left(1+c_{1}\right)\left(3+c_{1}\right) c_{2} c_{3}}{c_{1}^{2}} e_{n}^{4} \\
& +\cdots+O\left(e_{n}^{7}\right) .
\end{aligned}
$$

Using (27) and (29) in

$$
f\left[y_{n}, z_{n}\right]=\frac{f\left(y_{n}\right)-f\left(z_{n}\right)}{y_{n}-z_{n}},
$$


we get

$$
f\left[y_{n}, z_{n}\right]=c_{1}+\frac{\left(1+c_{1}\right) c_{2}^{2}}{c_{1}} e_{n}^{2}+\cdots+O\left(e_{n}^{7}\right) .
$$

Similarly,

$$
\begin{aligned}
f\left[x_{n}, y_{n}\right]= & c_{1}+c_{2} e_{n} \\
+ & \left(\left(1+\frac{1}{c_{1}}\right) c_{2}^{2}+c_{3}\right) e_{n}^{2}+\cdots+O\left(e_{n}^{7}\right), \\
f\left[x_{n}, z_{n}\right] & =c_{1}+c_{2} e_{n}+c_{3} e_{n}^{2}+\cdots+O\left(e_{n}^{7}\right) .
\end{aligned}
$$

Combining the above terms, we have

$$
\begin{aligned}
f^{\prime}\left(z_{n}\right) & =f\left[y_{n}, z_{n}\right]-f\left[x_{n}, y_{n}\right]+f\left[x_{n}, z_{n}\right] \\
& =c_{1}+\frac{\left(1+c_{1}\right) c_{2}\left(2 c_{2}^{2}-c_{1} c_{3}\right)}{c_{1}^{2}} e_{n}^{3}+\cdots+O\left(e_{n}^{7}\right) .
\end{aligned}
$$

Now dividing (33) by (29) and using the last step of (20), we have

$$
e_{n+1}=\frac{\left(1+c_{1}\right)^{2} c_{2}^{3}\left(c_{2}^{2}-c_{1} c_{3}\right)}{c_{1}^{5}} e_{n}^{6}+O\left(e_{n}^{7}\right)
$$

This proves that our first proposed method defined by (20) is a sixth-order derivative-free algorithm and satisfies the above error equation. This completes the proof.

Now we discuss the efficiency index of the new method by using Definition 3 as $p^{1 / q}$, where $p$ is the order of the method and $q$ is the number of function evaluations per iteration required of the method. It is easy to know that the number of function evaluations per iteration required by the method defined in algorithm 1 is four. So the efficiency index is $6^{1 / 4}=$ 1.5651 .

\section{Numerical Results}

In this section, we test the effectiveness of our new method. We have used second-order method of Steffensen (SM) [2], sixth-order method of Cordero et al. (CM) [3], six-order method of Soleymani and Hosseinabadi (SHM) [4], and six-order method of Yasmin and Iftikhar (YIM) [5] for comparison with our method to find the simple root of nonlinear equations. The test functions of $f(x)$ are listed in Table 1.

Numerical computations reported here have been carried out in a Mathematica 8.0 environment. Table 2 shows the difference of the root $\alpha$ and the approximation $x_{n}$ to $\alpha$, where $\alpha$ is the exact root computed with 800 significant digits (Digits :=800). The absolute values of the function $\left(\left|f\left(x_{n}\right)\right|\right)$, the difference between the approximated root $x_{n}$ and the exact root $\alpha$, the number of function evaluations (TNFE), and the computational order of convergence (COC) are also shown in Table 2. Here, COC is defined in Definition 4.

\section{Conclusions}

We have obtained a new Steffensen-type iterative method for solving nonlinear equations. The convergence order of this method is six and consists of four evaluations of the function per iteration, so it has an efficiency index equal to $6^{1 / 4}=$ 1.5651. Numerical examples also show that the numerical results of our new method, in equal iterations, improve the results of other existing methods.

\section{Conflict of Interests}

The author declares that there is no conflict of interests regarding the publication of this paper.

\section{Acknowledgment}

The author is grateful to the referees for their comments and suggestions that helped to improve the paper.

\section{References}

[1] W. Bi, H. Ren, and Q. Wu, "New family of seventh-order methods for nonlinear equations," Applied Mathematics and Computation, vol. 203, no. 1, pp. 408-412, 2008.

[2] D. Kincaid and W. Cheney, Numerical Analysis, Brooks/Cole, Pacific Grove, Calif, USA, 2nd edition, 1996.

[3] A. Cordero, J. L. Hueso, E. Martínez, and J. R. Torregrosa, "Steffensen type methods for solving nonlinear equations," Journal of Computational and Applied Mathematics, vol. 236, no. 12, pp. 3058-3064, 2012.

[4] F. Soleymani and V. Hosseinabadi, "New third- and sixth-order derivativefree techniques for nonlinear equations," Journal of Mathematics Research, vol. 3, no. 2, pp. 107-112, 2011.

[5] N. Yasmin and S. Iftikhar, "Some new Steffensen like three-step methods for solving nonlinear equations," International Journal of Pure and Applied Mathematics, vol. 82, pp. 557-572, 2013.

[6] W. Gautschi, Numerical Analysis, Birkhäuser, Boston, Mass, USA, 1997.

[7] S. Weerakoon and T. G. I. Fernando, "A variant of Newton's method with accelerated third-order convergence," Applied Mathematics Letters, vol. 13, no. 8, pp. 87-93, 2000.

[8] M. Basto, V. Semiao, and F. L. Calheiros, "A new iterative method to compute nonlinear equations," Applied Mathematics and Computation, vol. 173, no. 1, pp. 468-483, 2006.

[9] J. Kou, Y. Li, and X. Wang, "Modified Halley's method free from second derivative," Applied Mathematics and Computation, vol. 183, no. 1, pp. 704-708, 2006.

[10] M. Dehghan and M. Hajarian, "Some derivative free quadratic and cubic convergence iterative formulas for solving nonlinear equations," Computational and Applied Mathematics, vol. 29, no. 1, pp. 19-30, 2010. 


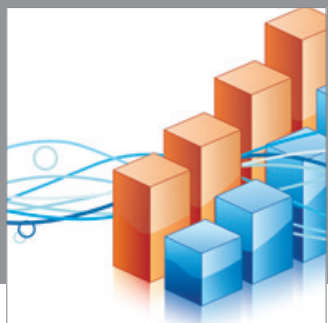

Advances in

Operations Research

mansans

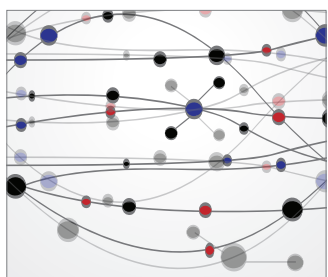

The Scientific World Journal
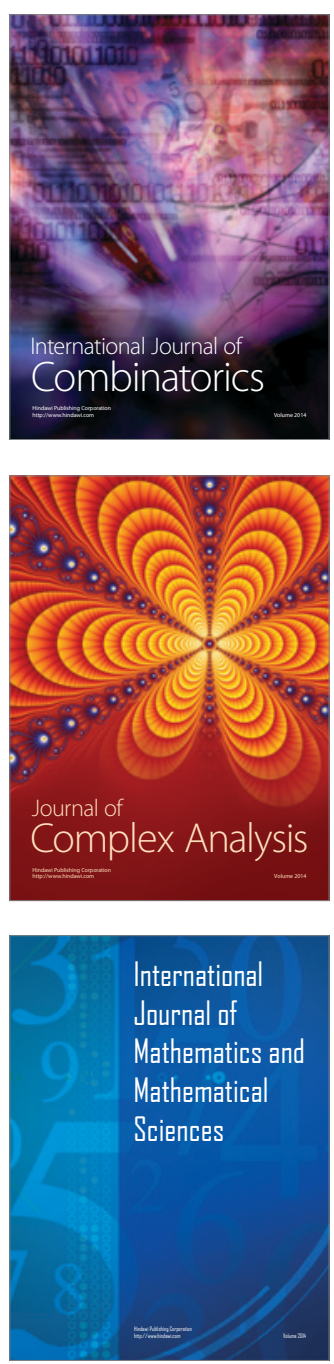
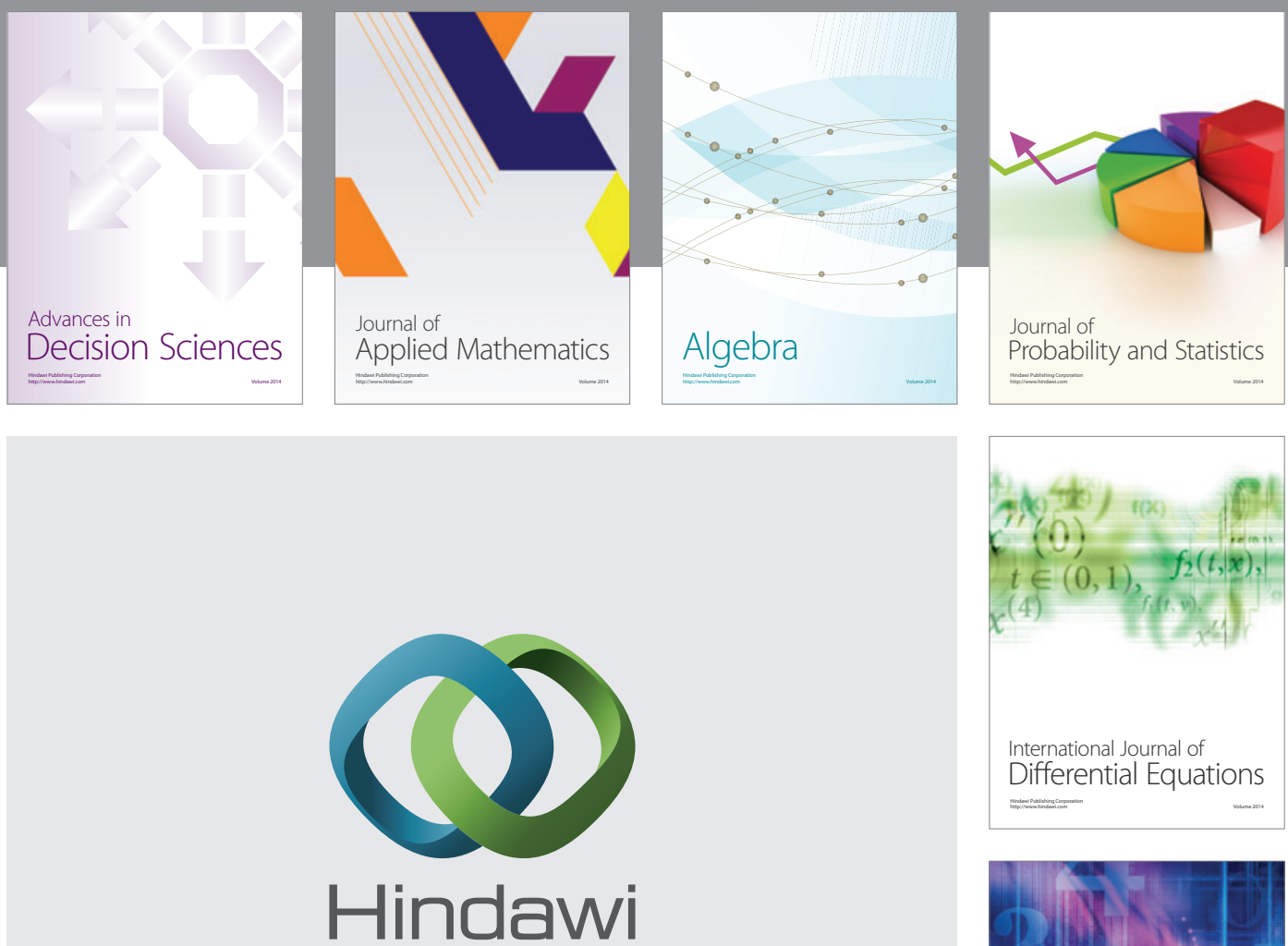

Submit your manuscripts at http://www.hindawi.com
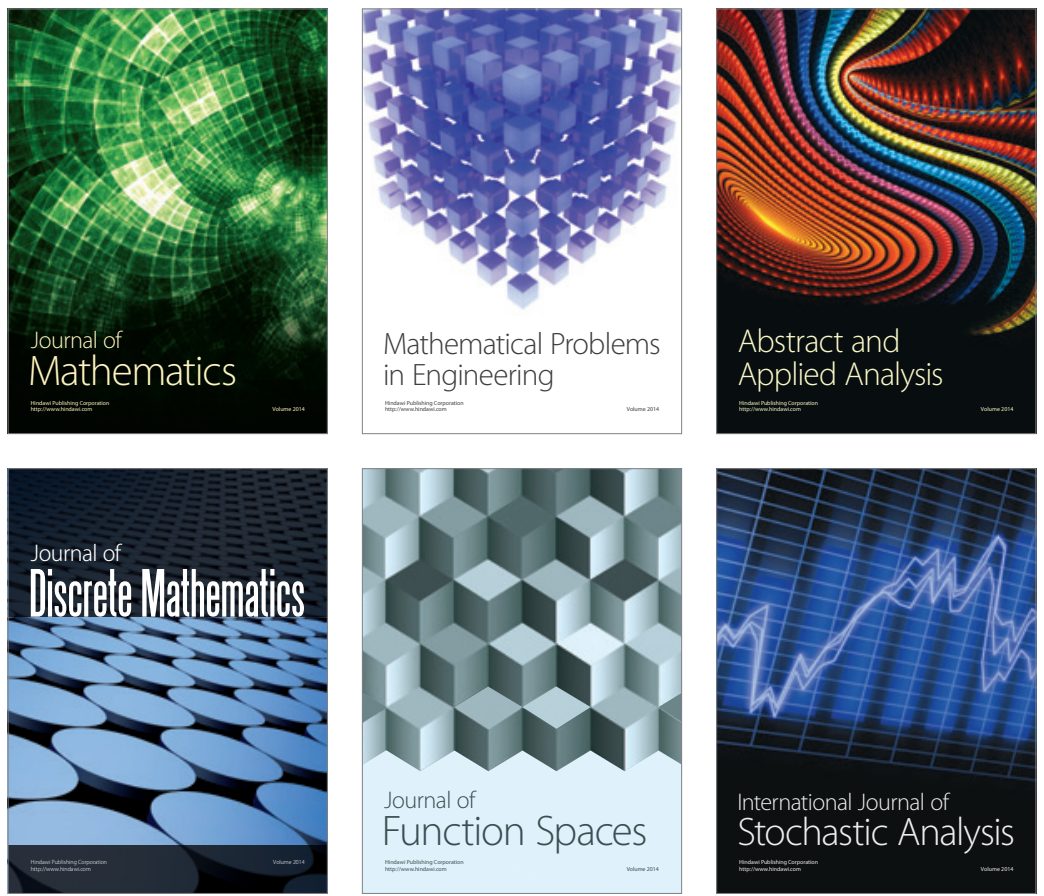

Journal of

Function Spaces

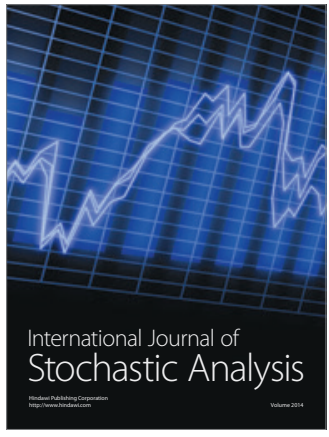

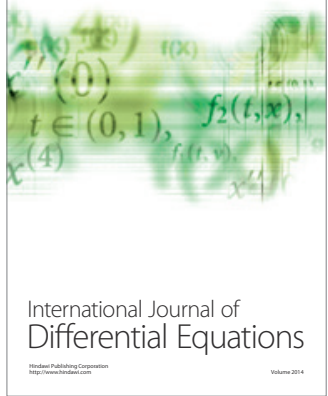
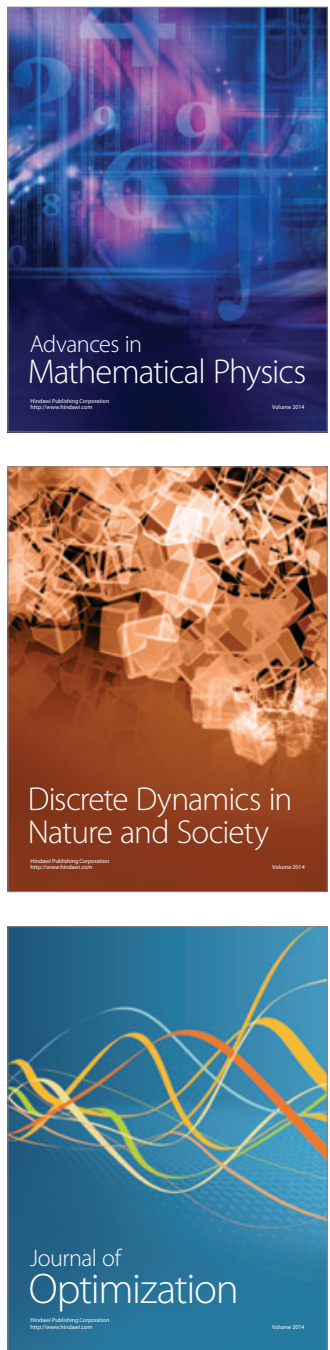